\title{
Changes in the Salivary Proteome Associated With Canine Pyometra
}

\author{
Lorena Franco-Martínez ${ }^{1}$, Anita Horvatić ${ }^{2}$, Andrea Gelemanović ${ }^{3}$, Marko Samardžija ${ }^{2}$, \\ Vladimir Mrljak ${ }^{2}$, María Dolores Contreras-Aguilar ${ }^{1}$, Silvia Martínez-Subiela ${ }^{1}$, \\ Roman Dąbrowski ${ }^{4 *}$ and Asta Tvarijonaviciute ${ }^{1}$
}

${ }^{1}$ Interdisciplinary Laboratory of Clinical Analysis, Interlab-UMU, Regional Campus of International Excellence 'Campus Mare Nostrum', University of Murcia, Murcia, Spain, ${ }^{2}$ Faculty of Veterinary Medicine, University of Zagreb, Zagreb, Croatia,

${ }^{3}$ Mediterranean Institute for Life Sciences (MedILS), Split, Croatia, ${ }^{4}$ Department and Clinic of Animal Reproduction, Faculty of Veterinary Medicine, University of Life Sciences in Lublin, Lublin, Poland

\section{OPEN ACCESS}

Edited by:

Arumugam Kumaresan,

National Dairy Research Institute

(ICAR), India

Reviewed by:

Martin G. Maquivar,

Washington State University,

United States

Firdous Ahmad Khan,

St. George's University, Grenada

*Correspondence:

Roman Dąbrowsk

roman.dabrowski@up.lublin.pl

Specialty section:

This article was submitted to

Animal Reproduction -

Theriogenology,

a section of the journal

Frontiers in Veterinary Science

Received: 18 February 2020

Accepted: 27 April 2020

Published: 11 June 2020

Citation:

Franco-Martínez L, Horvatić A, Gelemanović A, Samardžija M Mrljak V, Contreras-Aguilar MD, Martínez-Subiela S, Dąbrowski $R$ and Tvarijonaviciute A (2020) Changes in the Salivary Proteome Associated With Canine Pyometra.

Front. Vet. Sci. 7:277 doi: 10.3389/fvets.2020.00277
The present study evaluated for the first time changes in the saliva proteome in bitches with pyometra through a high-throughput quantitative proteomic analysis. The aims were to explore whether saliva composition could reflect the physiopathological changes occurring in canine pyometra and to identify potential biomarkers of the disease. Saliva samples from six healthy $(H)$ and six bitches with pyometra $(P)$ were analyzed using tandem mass tags-based approach. Additionally, 15 samples were used for the validation of changes in haptoglobin ( $\mathrm{Hp}$ ) concentration in saliva of dogs with pyometra. Proteomic analysis quantified 707 proteins in saliva. Comparison of the two groups revealed 16 unique proteins significantly modulated in saliva, with S100A calcium-binding protein 12 (S100A12), vimentin, and Hp the most up-regulated in canine pyometra. According to PANTHER (Protein Analysis Through Evolutionary Relationships) classification tool, these proteins are mainly related to proinflammatory mediators, acute-phase proteins, and sepsis. In conclusion, it can be stated that there are changes in various proteins in saliva in canine pyometra reflecting different physiopathological changes occurring in this disease. These proteins could be a source of potential non-invasive biomarkers for this disease that should be confirmed in future studies.

Keywords: biomarker, dog, proteomics, pyometra, saliva, tandem mass tags

\section{INTRODUCTION}

Pyometra, which literally means "pus-filled uterus," is the most common disease of the uterus in intact adult bitches after non-pregnant estrus cycles (1). It is a post-estrum suppurative bacterial infection of the uterus, which may cause accumulation of inflammatory exudate and produces a variety of clinical manifestations (2). Generally, the clinical signs of closed-cervix pyometra are more severe because of the presence of enlarged uterus and endotoxemia, increasing the risks of uterine rupture and the systemic inflammatory response syndrome (3). Thus, a wide range of clinical signs can be observed from subclinical to a fatal illness, which could make the early diagnosis of pyometra challenging, especially when there is no vaginal discharge (2).

Hormonal and bacterial factors are involved in the development of canine pyometra. The higher concentrations of progesterone during the luteal phase promote changes in the uterus including an increase in glandular activity and secretions, and lesser contractions and leukocyte response (4), enabling physiological pregnancy, although they are also ideal for the promotion of microbial growth and pyometra. Because estrogens increase uterine sensitivity to progesterone, the risk of 
pyometra is increased in older bitches or in those under estrogen therapy $(5,6)$. However, there is a scarcity of information regarding the complex pathogenesis of canine pyometra (2), and the knowledge of the changes that occur in saliva proteome in bitches with pyometra could help to clarify this pathogenesis and detect possible potential biomarkers of the disease.

The use of saliva provides several advantages compared to samples that are collected by invasive methods such as blood, being safer for the personnel and the patient, easy and pain-free to collect, and reducing sampling stress (7). Saliva usually presents a higher variability of proteins in comparison to serum and can be used to monitor disease status providing additional knowledge of disease pathophysiology and reveal potential new biomarkers. The salivary proteome in 36 healthy dogs was analyzed using nanoscale liquid chromatography-tandem mass spectrometry, identifying a total of 2,491 proteins (8). Because saliva may reflect the overall physiological status, it is envisioned that it will be used increasingly in relation to diseases' early diagnosis or monitoring (9). In dogs, saliva has been usefully employed for the diagnosis of infectious (10-12) and metabolic (13) diseases, among others. Saliva composition is also known to be modulated in canine pyometra because increased and decreased concentrations of adenosine deaminase and adiponectin, respectively_biomarkers related to of inflammation-were found in bitches with pyometra in comparison to healthy ones $(14,15)$. Therefore, a detailed overview of the possible changes in salivary protein composition could improve the understanding of the physiopathology of canine pyometra, as well as point out possible biomarkers of the disease.

Over the last years, the sensitivity of the proteomic analysis has been greatly improved by the discovery of novel technologies such as isobaric tags (16-18). Those technologies have several advantages over gel-based proteomics such as improved sensitivity and reproducibility (16-18). Tandem mass tag (TMT) allows the relative simultaneous quantification of differentially labeled peptides (19) in several biological samples. The approach has been successfully applied in the study of several canine infectious diseases such as parvovirus or leishmaniasis, among others $(11,20)$. Although the high time and costs of proteomics in comparison to other analysis limited their usefulness for direct routine clinical applications, these techniques are increasingly used as the initial point for the search of biomarkers. However, to the authors' best knowledge, the possible changes in salivary proteome in canine pyometra have not been yet studied.

The objective of the present study was to evaluate possible changes in the salivary proteome in bitches with pyometra compared to healthy ones. This would highly contribute to gaining knowledge about the reflection of physiopathological changes in saliva associated with the disease and the use of saliva as a source of potential non-invasive biomarkers of this disease.

\section{MATERIALS AND METHODS}

\section{Animals and Saliva Sampling}

Twenty-seven client-owned bitches of different breeds presented to the Department and Clinic of Animal Reproduction, Faculty of
Veterinary Medicine, University of Life Sciences, Lublin, Poland, from November 2018 to October 2019 were included in the study.

All animals were in diestrus, and according to health status, dogs were allocated into two groups. One group $(\mathrm{H})$ consisted of bitches that were classified as healthy after a complete physical examination and hematological and serum biochemistry. The second group $(\mathrm{P})$ comprised bitches diagnosed with open-cervix pyometra. This diagnosis was based on clinical examination (with all cases showing pyrexia, apathy, polydipsia-polyuria, and anorexia), hematology (with increased white blood cell count and band neutrophil counts), serum biochemistry (with increased globulins and C-reactive protein), and abdominal ultrasound findings consistent with pyometra, as described previously (14).

In the pyometra group, samples were collected at the moment of diagnosis and before any treatment; according to owners, bitches showed compatible clinical signs 03 days before their presentation to the Department and Clinic of Animal Reproduction. Immediately after surgery, the bacteriological examination of the pus collected from the uterus showed Escherichia coli in all cases.

Exclusion criteria included the presence of gingivitis or any other oral or systemic diseases, including infectious, metabolic, or endocrine. In addition, in the case of $\mathrm{P}$ group, bitches were not included if presented with closed-cervix pyometra.

The dogs were randomly selected in the database from those that met the inclusion criteria. Six animals of each group were selected for proteomic study (two mixed breeds, two Labrador retriever, and two German shepherd, body weight $35 \pm 9.3 \mathrm{~kg}$, aged $8.8 \pm 2.09$ years) for the H group and three mixed breeds: two German Shepherd, one Siberian husky, body weight $30.5 \pm$ $9.7 \mathrm{~kg}$, aged $9.1 \pm 3.29$ years for $\mathrm{P}$ group), whereas samples of the rest of the animals (four mixed breeds, two German Shepherd, one Bullterrier, body weight $18.0 \pm 10.7 \mathrm{~kg}$, aged $8.3 \pm 3.45$ years for $\mathrm{H}$; and five mixed breeds and one of each of Dachshund, Pekinese, and Yorkshire Terrier; body weight $12.0 \pm 8.9 \mathrm{~kg}$, aged $8.8 \pm 2.67$ years for $\mathrm{P}$ ) were used in the validation study. All the procedures were approved by the University of Lublin Institutional Animal Care and Ethics Committee (approval no. 27/2015), and written consent was obtained from the owners.

For sample collection, at least $0.5 \mathrm{~mL}$ of total saliva was collected from each patient by introducing a small piece of sponge in the mouth, as described elsewhere (21). When the sponges were thoroughly moistened, they were placed into collection devices (Salivette saliva collection tube/V-bottom; Sarstedt, Aktiengesellschaft \& Co, Nümbrecht, Germany), centrifuged $\left(3,000 \times \mathrm{g}\right.$ for $\left.10 \mathrm{~min}, 4^{\circ} \mathrm{C}\right)$, and the supernatant was stored at $-80^{\circ} \mathrm{C}$ until analysis (22).

\section{Proteomic Study and Liquid Chromatography-Tandem Mass Spectrometry Analysis}

From each sample, $35 \mu \mathrm{g}$ of protein was subjected to reduction, alkylation, digestion, and labeling using 6-plex TMT 
reagents according to manufacturer instructions (Thermo Fisher Scientific, Waltham, MA USA) as described previously (23).

Dionex Ultimate 3000 RSLC nano-flow system (Dionex, Camberley, UK) and Orbitrap Q Exactive Plus mass spectrometer (Thermo Fisher Scientific) were used for the liquid chromatography-tandem mass spectrometry, as described elsewhere (23). SEQUEST algorithm, Proteome Discoverer (version 2.0., Thermo Fisher Scientific), was used for peptide identification and relative quantification. NCBI database search against Canis lupus FASTA files was performed considering two trypsin missed cleavage sites, precursor tolerance of $10 \mathrm{ppm}$, and fragment mass tolerance of 0.02 Da. Percolator algorithm within the Proteome Discoverer workflow was used to determine the false discovery rate (FDR) for peptide identification, which was set at $1 \%$. In cases where GI accession number was described as unnamed, BLAST analysis and sequence comparison public database (NCBI) information were performed, and the result with the higher identity and query cover were included $(>98 \%$ in all cases).

\section{Statistical Analysis}

Proteins with fewer than two unique peptides and those with more than $90 \%$ missing data in all samples were removed from the analysis. Sample outliers were detected and removed for each group and protein using the Dixon's test from $\mathrm{R}$ package outliers v0.14 (24). Shapiro-Wilk test showed that the majority of the analyzed proteins did not follow a normal distribution; therefore, Wilcoxon-Mann-Whitney test was performed to test the difference in protein abundance between groups. Fold change between two groups was calculated as mean $(\mathrm{P}) /$ mean $(\mathrm{H})$. Statistics were performed with R v3.2.2 (25).

Heatmap was designed using R package ggplot2 v3.1.1 (26), ggdendro v0.1-20 (27), and pheatmap v1.0.12 (28).

Genes encoding the differentially expressed proteins between $\mathrm{H}$ and $\mathrm{P}$ groups were used to determine the Gene ontology (GO) terms overrepresented in CMT using Protein Analysis Through Evolutionary Relationships (PANTHER) classification tool (http://www.pantherdb.org/).

\section{Validation of Haptoglobin as Salivary Biomarker for Canine Pyometra}

Haptoglobin (Hp) in saliva was selected for validation because it showed 2-fold higher concentrations in bitches with pyometra in comparison to healthy ones in the proteomic analysis.

Haptoglobin was measured by a time-resolved fluorometrybased immunoassay described elsewhere and validated for its use for canine saliva (29). Haptoglobin concentrations were expressed in $\mu \mathrm{g} / \mathrm{mL}$.

\section{RESULTS}

\section{High-Resolution Quantitative Proteomic Analysis}

After the removal of proteins with fewer than two unique peptides, missing data, outliers, and $<5 \%$ FDR, 707 proteins remained to be analyzed (Supplementary Table 1). WilcoxonMann-Whitney test pointed out statistically significantly different abundance between $\mathrm{H}$ and $\mathrm{P}$ groups in 16 unique proteins, as shown in Table 1 and Figure 1. Of those, only one protein named DMBT-1 (deleted in malignant brain tumors 1) was down-regulated, whereas 15 were up-regulated in canine pyometra.

These differentially expressed proteins in saliva between $\mathrm{H}$ and $\mathrm{P}$ groups were used for qualitative analysis in terms of functional clusters, according to the PANTHER classification system (http://www.pantherdb.org). The identified differentially modulated proteins between $\mathrm{H}$ and $\mathrm{P}$ had two molecular functions: catalytic activity (80\%) and binding (20\%). Six different biological processes were involved, being metabolic and cellular process the majoritarian with 39.9 and $33.3 \%$ of proteins, respectively. Six biological pathways were involved, being blood coagulation, integrin signaling pathway, and plasminogen activating cascade the most represented with $22.2 \%$ of proteins each. Finally, in relation with protein class, $41 \%$ were hydrolases, followed by oxidoreductases (25\%).

\section{Validation of Haptoglobin in Saliva}

When Hp was measured in saliva, it was significantly higher in bitches with canine pyometra [median (25th-75th percentile) [3.09 $(1.39-10.24) \mu \mathrm{g} / \mathrm{mL}]$ in comparison to healthy ones [0.24 $(0.19-0.61) \mu \mathrm{g} / \mathrm{mL}](p<0.001)$.

\section{DISCUSSION}

This is the first study in which salivary proteome was evaluated in bitches with pyometra and compared to healthy controls, showing 16 proteins differentially expressed between the two groups that reflect the activation of different biological pathways and that can potentially be of use as non-invasive biomarkers of this disease. To the best of the authors' knowledge, most of these proteins are described for the first time in saliva in canine pyometra.

S100A12, vimentin, and $\mathrm{Hp}$ were the proteins most upregulated in canine pyometra. S100A proteins interact with endothelium cells, mononuclear phagocytes, and lymphocytes, participating in the immune cell activation and the generation of proinflammatory mediator (30). In line with our findings, a marked upregulation of S100A12 gene expression in the uterus of bitches with canine pyometra in comparison to healthy controls has been reported (31). Also, in humans, S100A12 has been proposed as a feasible biomarker of diagnostic and prognostic in sepsis, showing higher plasma concentration in patients with deadly septic shock in comparison to healthy individuals and survivor patients (32), and showed high sensitivity and specificity as serum biomarker of neonatal sepsis (33). Vimentin is a type of intermediate filament protein that is up-regulated during epithelial-to-mesenchymal transition, a process that occurs during neural development, wound healing, and cancer metastasis (34). Recently, it has been associated with sepsis (35), and therefore, this could 
TABLE 1 | In saliva, there were 16 proteins identified with significantly different abundance between bitches with pyometra and healthy controls.

\begin{tabular}{|c|c|c|c|c|c|c|}
\hline GI accession & Gene symbol & Description & $\boldsymbol{P}$ & Fold change & $\begin{array}{l}\text { Median (25th-75th } \\
\text { interquartile) } \\
\text { healthy }\end{array}$ & $\begin{array}{l}\text { Median (25th-75th } \\
\text { interquartile) } \\
\text { pyometra }\end{array}$ \\
\hline \multicolumn{7}{|c|}{ Proteins downregulated in pyometra when compared to $\mathrm{HC}$} \\
\hline 928186547 & DMBT1 & $\begin{array}{l}\text { Deleted in malignant brain tumors } \\
1 \text { protein-like }\end{array}$ & 0.026 & 0.437 & $1.403(1.289-1.518)$ & $0.724(0.608-0.841)$ \\
\hline \multicolumn{7}{|c|}{ Proteins upregulated in pyometra when compared to HC } \\
\hline 558695388 & PLG & Plasminogen precursor & 0.032 & 1.343 & $0.731(0.624-0.838)$ & $1.061(1.026-1.096)$ \\
\hline 73988725 & HPX & Hemopexin & 0.032 & 1.403 & $0.615(0.431-0.8)$ & $1.085(1.02-1.15)$ \\
\hline 1005261202 & ARF1 & ADP-ribosylation factor 1 & 0.040 & 1.484 & $0.708(0.676-0.74)$ & $0.878(0.753-1.003)$ \\
\hline 1418330752 & ARF17 & $\begin{array}{l}\text { ADP-ribosylation factor-like } \\
\text { 17-like }\end{array}$ & 0.040 & 1.484 & $0.708(0.676-0.74)$ & $0.878(0.753-1.003)$ \\
\hline 545545650 & ARF3 & ADP-ribosylation factor 3 & 0.040 & 1.484 & $0.708(0.676-0.74)$ & $0.878(0.753-1.003)$ \\
\hline 545536994 & LDHA & L-lactate dehydrogenase A chain & 0.032 & 1.510 & $0.732(0.65-0.814)$ & $1.117(1.023-1.211)$ \\
\hline 57092971 & $\mathrm{MDH} 1$ & $\begin{array}{l}\text { Malate dehydrogenase, } \\
\text { cytoplasmic }\end{array}$ & 0.032 & 1.538 & $0.644(0.588-0.7)$ & $1.078(0.912-1.245)$ \\
\hline 1418315363 & CFL1 & Cofilin-1-like & 0.040 & 1.624 & $0.722(0.632-0.813)$ & $1.051(0.719-1.383)$ \\
\hline 89573987 & $\mathrm{IDH} 1$ & Isocitrate dehydrogenase 1 & 0.032 & 1.647 & $0.707(0.601-0.813)$ & $0.889(0.723-1.055)$ \\
\hline 1418218016 & LRG1 & Leucine-rich alpha-2-glycoprotein & 0.032 & 1.698 & $0.647(0.423-0.872)$ & $1.145(1.025-1.265)$ \\
\hline 928134045 & ENO3 & Beta-enolase & 0.030 & 1.729 & $0.601(0.522-0.681)$ & $0.832(0.589-1.076)$ \\
\hline 345800677 & ENO1 & Alpha-enolase & 0.030 & 1.859 & $0.524(0.349-0.7)$ & $0.839(0.577-1.102)$ \\
\hline 258499 & $\mathrm{HP}$ & Haptoglobin heavy chain & 0.030 & 2.047 & $0.573(0.452-0.695)$ & 0.993 (0.65-1.337) \\
\hline 559098393 & VIM & Vimentin & 0.032 & 2.069 & $0.559(0.465-0.654)$ & $0.991(0.612-1.371)$ \\
\hline 1418313614 & S100A12 & Protein S100-A12-like & 0.017 & 2.149 & $0.478(0.392-0.565)$ & $0.942(0.691-1.194)$ \\
\hline
\end{tabular}

explain high concentrations of vimentin found in saliva in a pyometra group.

Haptoglobin is considered a moderate acute-phase protein in dogs, increasing its concentrations $\sim 2$ - to 5 -fold in serum under inflammation (36). Increases in serum $\mathrm{Hp}$ have been reported in a variety of diseases of the dog including heartworm (37) or leishmaniasis (38). Serum Hp has been also proven of use for monitoring the postoperative period in bitches with pyometra (39). The results of the proteomic analysis in relation with salivary Hp concentrations were further verified by a timeresolved fluorometry-based immunoassay for its use in canine saliva, showing an increase in $\mathrm{Hp}$ in saliva of bitches with pyometra in comparison to healthy ones. Our results are in line with a previous report in which $\mathrm{Hp}$ in saliva increases in a group of dogs with different diseases including three cases of canine pyometra (29).

Finally, the differentially modulated proteins between $\mathrm{H}$ and $\mathrm{P}$ were mainly related to catalytic activity (80\%) and binding (20\%) molecular functions. Catalytic activity was represented by proteins including $\mathrm{Hp}$, plasminogen, and hemopexin. According to PANTHER classification systems, these proteins participate in important roles such as regulation of cell death, inflammatory response, blood coagulation, and metabolic processes, respectively. On the other hand, binding molecular function was represented by ADP-ribosylation factors, which are G proteins that participate in the intracellular and vesicle-mediated transport. The knowledge of the biological roles of the proteins in saliva affected by canine pyometra could be of utility for the increased knowledge of the pathophysiology of the disease and could point out novel insights for diagnostic, prognostic, or monitoring biomarkers, as well as potential therapeutic targets.

The relatively small sample size used is one of the main limitations of this report, and therefore, this study should be considered as a pilot study. However, the sample size is higher than the minimum recommended of three replicates (40) and is in concordance with similar proteomic studies (41). Second, some of the proteins differently modulated in saliva in canine pyometra are not specific to this condition, and therefore, their possible value as confirmatory biomarkers for diagnosis of pyometra would be questionable. However, their use as prognostic indicators or for monitoring response to treatment might be worth further research in the future. Additionally, because only bitches without oral alterations including gingivitis were included, the applications of these biomarkers in clinical situations where oral alterations are present should be performed with caution. Finally, in order to use a more homogeneous group, only open cervix pyometra cases were included in the study. However, in the future, it would be of interest to evaluate also close pyometra and explore if in these cases there could be specific markers that could contribute to their detection.

In conclusion, it can be stated that there are changes in various proteins in saliva in canine pyometra reflecting 

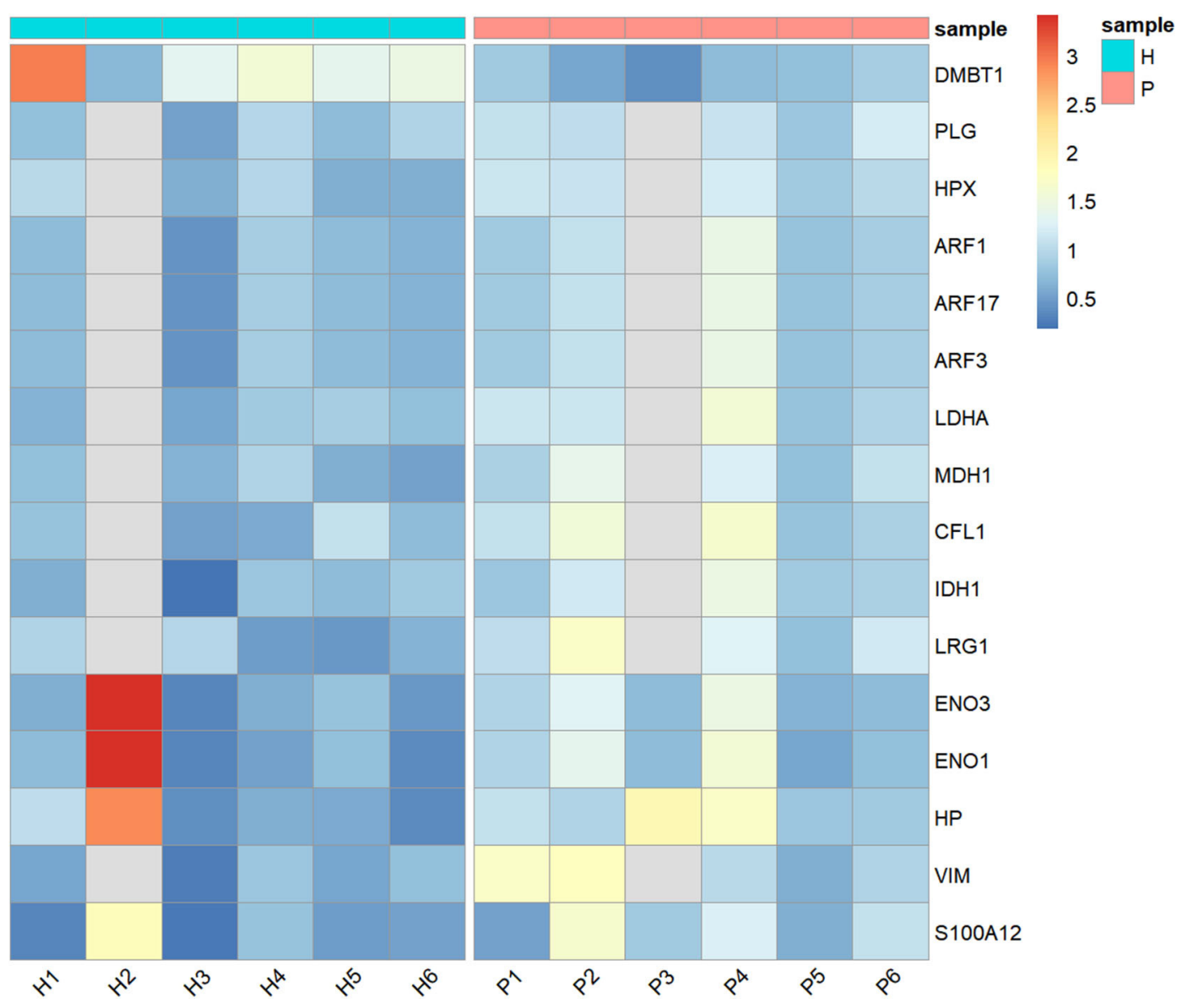

RF3

$\mathrm{HA}$

$\mathrm{DH} 1$

FL1

1

RG1

NO3

NO1 
Commission ERA chair FP7 grant (VetMedZg \#621394), and by the Seneca Foundation-Agency of Science and Technology of the Region of Murcia through the Subprogram of Support to the Scientific Leadership and the Transition to the Independent Investigation (20649/JLI/18).

\section{REFERENCES}

1. Gilbert R. Diagnosis and treatment of pyometra in bitches and queens. Comp Cont Educ Pr. (1992) 14:777-83.

2. Hagman R. Pyometra in small animals. Vet Clin North Am Small Anim Pract. (2018) 48:639-61. doi: 10.1016/j.cvsm.2018.03.001

3. Jitpean S, Ambrosen A, Emanuelson U, Hagman R. Closed cervix is associated with more severe illness in dogs with pyometra. BMC Vet Res. (2017) 13:11. doi: 10.1186/s12917-016-0924-0

4. Cox JE. Progestagens in bitches: a review. J Small Anim Pract. (1970) 11:75978. doi: 10.1111/j.1748-5827.1970.tb05587.x

5. Buhi WC, Thatcher MJ, Shille VM, Alvarez IM, Lannon AP, Johnson J. Synthesis of uterine endometrial proteins during early diestrus in the cyclic and pregnant dog, and after estrogen and progesterone treatment. Biol Reprod. (1992) 47:326-36. doi: 10.1095/biolreprod47.3.326

6. Nelson RW, Feldman EC. Pyometra. Vet Clin North Am Small Anim Pract. (1986) 16:561-76. doi: 10.1016/S0195-5616(86)50061-9

7. Lindsay A, Costello JT. Realising the potential of urine and saliva as diagnostic tools in sport and exercise medicine. Sport Med. (2016) 47:1131. doi: 10.1007/s40279-016-0558-1

8. Torres SMF, Furrow E, Souza CP, Granick JL, De Jong EP, Griffin TJ, et al. Salivary proteomics of healthy dogs: an in depth catalog. PLoS ONE. (2018) 13:e0191307. doi: 10.1371/journal.pone.0191307

9. Tabak LA. A Revolution in biomedical assessment: the development of salivary diagnostics. J Dent Educ. (2001) 65:1335-9.

10. Cantos-Barreda A, Escribano D, Bernal LJ, Cerón JJ, Martínez-Subiela S. Quantification of anti-leishmania antibodies in saliva of dogs. Vet Parasitol. (2017) 242:54-8. doi: 10.1016/j.vetpar.2017.05.017

11. Franco-Martínez L, Tvarijonaviciute A, Horvatić A, Guillemin N, Cerón JJ, Escribano D, et al. Changes in salivary analytes in canine parvovirus: a highresolution quantitative proteomic study. Comp Immunol Microbiol Infect Dis. (2018) 60:1-10. doi: 10.1016/j.cimid.2018.09.011

12. Jankowski M, Spuzak J, Kubiak K, Glinska-Suchocka K, Biernat M. An evaluation of the usefulness of invasive and non-invasive methods used to diagnose Helicobacter spp. infections in dogs. Pol J Vet Sci. (2017) 20:4919. doi: 10.1515/pjvs-2017-0059

13. Lucena S, Varela Coelho A, Anjo SI, Manadas B, Mrljak V, Capela e Silva $\mathrm{F}$, et al. Comparative proteomic analysis of saliva from dogs with and without obesity-related metabolic dysfuntion. J Proteomics. (2019) 201:6572. doi: 10.1016/j.jprot.2019.04.010

14. Tecles F, Escribano D, Contreras-Aguilar MD, Rubio CP, Szczubiał M, Cerón JJ, et al. Evaluation of adenosine deaminase in saliva and serum, and salivary $\alpha$-amylase, in canine pyometra at diagnosis and after ovariohysterectomy. Vet J. (2018) 236:102-10. doi: 10.1016/j.tvjl.2018.04.018

15. Dabrowski R, Wdowiak A, Contreras-Aguilar MD, FrancoMartinez L, Muñoz-Prieto A, Szczubiał $M$, et al. Serum and salivary adiponectin dynamics in septic and non-septic systemic inflammation in a canine model. Vet Immunol Immunopathol. (2020) 219:109961. doi: 10.1016/j.vetimm.2019.109961

16. Baeumlisberger D, Arrey TN, Rietschel B, Rohmer M, Papasotiriou DG, Mueller B, et al. Labeling elastase digests with TMT: informational gain by identification of poorly detectable peptides with MALDI-TOF/TOF mass spectrometry. Proteomics. (2010) 10:3905-9. doi: 10.1002/pmic.2010 00288

17. Dayon L, Turck N, Garcia-Berrocoso T, Walter N, Burkhard PR, Vilalta A, et al. Brain extracellular fluid protein changes in acute stroke patients. $J$ Proteome Res. (2011) 10:1043-51. doi: 10.1021/pr101123t

\section{SUPPLEMENTARY MATERIAL}

The Supplementary Material for this article can be found online at: https://www.frontiersin.org/articles/10.3389/fvets. 2020.00277/full\#supplementary-material

18. Giron P, Dayon L, Turck N, Hoogland C, Sanchez J-C. Quantitative analysis of human cerebrospinal fluid proteins using a combination of cysteine tagging and amine-reactive isobaric labeling. J Proteome Res. (2011) 10:24958. doi: 10.1021/pr100535f

19. Ross PL, Huang YN, Marchese JN, Williamson B, Parker K, Hattan S, et al. Multiplexed protein quantitation in Saccharomyces cerevisiae using amine-reactive isobaric tagging reagents. Mol Cell Proteomics. (2004) 3:115469. doi: 10.1074/mcp.M400129-MCP200

20. Martínez-Subiela S, Ceron JJ, Yilmaz Z, Martinez-Subiela S, Horvatic A, Escribano D, et al. Identification of novel biomarkers for treatment monitoring in canine leishmaniosis by high-resolution quantitative proteomic analysis. Vet Immunol Immunopathol. (2017) 191:60-7. doi: 10.1016/j.vetimm.2017.08.004

21. Parra M, Tecles F, Martinez-Subiela S, Ceron J. C-reactive protein measurement in canine saliva. J Vet Diagnostic Investig. (2005) 17:13944. doi: 10.1177/104063870501700207

22. Contreras-Aguilar MD, Tecles F, Martínez-Subiela S, Escribano D, Bernal LJ, Cerón JJ. Detection and measurement of alpha-amylase in canine saliva and changes after an experimentally induced sympathetic activation. BMC Vet Res. (2017) 13:266. doi: 10.1186/s12917-0171191-4

23. Horvatić A, Guillemin N, Kaab H, McKeegan D, O'Reilly E, Bain M, et al. Quantitative proteomics using tandem mass tags in relation to the acute phase protein response in chicken challenged with Escherichia coli lipopolysaccharide endotoxin. J Proteomics. (2019) 192:64-77. doi: 10.1016/j.jprot.2018.08.009

24. Komsta L. Package 'Outliers.' R Topics Document (2015).

25. RCT. R: A Language and Environment for Statistical Computing. Vienna: R Foundation Statistical Computation (2013).

26. Wickham H. ggplot2: Elegant Graphics for Data Analysis, New York, NY (2009).

27. Vries A, de Ripley BD. ggdendro: Create Dendrograms and Tree Diagrams Using "ggplot2.”. (2016). Available at: https://cran.r-project.org/web/packages/ ggdendro/ggdendro.pdf (accessed June 14, 2019).

28. Kolde R. pheatmap: Pretty Heatmaps in R Package. R Packag Version 61 (2012).

29. Parra MD, Väisänen V, Cerón JJ. Development of a time-resolved fluorometry based immunoassay for the detemination of canine haptoglobin in various body fluids. Vet Res. (2005) 36:117-29. doi: 10.1051/vetres:2004054

30. Hofmann MA, Drury S, Fu C, Qu W, Taguchi A, Lu Y, et al. RAGE mediates a novel proinflammatory axis: a central cell surface receptor for S100/calgranulin polypeptides. Cell. (1999) 97:889-901. doi: 10.1016/S0092-8674(00)80801-6

31. Bukowska D, Kempisty B, Zawierucha P, Jopek K, Piotrowska $\mathrm{H}$, Antosik P, et al. Microarray Analysis of Inflammatory Response-Related Gene Expression in the Uteri of Dogs With Pyometra. J Biol Regul Homeost Agents. (2014) 28: 637-48.

32. Dubois C, Marcé D, Faivre V, Lukaszewicz AC, Junot C, Fenaille $F$, et al. High plasma level of S100A8/S100A9 and S100A12 at admission indicates a higher risk of death in septic shock patients. Sci Rep. (2019) 9:15660. doi: 10.1038/s41598-01952184-8

33. Tosson AMS, Glaser K, Weinhage T, Foell D, Aboualam MS, Edris AA, et al. Evaluation of the S100 protein A12 as a biomarker of neonatal sepsis. J Matern Fetal Neonatal Med. (2019) 1-191. doi: 10.1080/14767058.2018.1560411

34. Raskin R, Meyer D. Canine and Feline Cytology. Amsterdam: Elsevier Inc. (2010). 
35. Strela FB, Brun BF, Berger RCM, Melo S, de Oliveira EM, Barauna VG, et al. Lipopolysaccharide exposure modulates the contractile and migratory phenotypes of vascular smooth muscle cells. Life Sci. (2020) 241:117098. doi: 10.1016/j.lfs.2019.117098

36. Cerón JJ, Eckersall PD, Martínez-Subiela S. Acute phase proteins in dogs and cats: current knowledge and future perspectives. Vet Clin Pathol. (2005) 34:85-99. doi: 10.1111/j.1939-165X.2005.tb00019.x

37. Carretón E, Cerón JJ, Martínez-Subiela S, Tvarijonaviciute A, CaroVadillo A, Montoya-Alonso JA. Acute phase proteins and markers of oxidative stress to assess the severity of the pulmonary hypertension in heartworm-infected dogs. Parasit Vectors. (2017) 10(Suppl. 2):477. doi: 10.1186/s13071-017-2426-8

38. Martinez-Subiela S, Strauss-Ayali D, Cerón JJ, Baneth G. Acute phase protein response in experimental canine leishmaniosis. Vet Parasitol. (2011) 180:197202. doi: 10.1016/j.vetpar.2011.03.032

39. Dabrowski R, Kostro K, Lisiecka U, Szczubiał M, Krakowski L. Usefulness of C-reactive protein, serum amyloid A component, and haptoglobin determinations in bitches with pyometra for monitoring early post-ovariohysterectomy complications. Theriogenology. (2009) 72:471-6. doi: 10.1016/j.theriogenology.2009.03.017
40. Westermeier R, Naven T, Hopker H-R, Wiley InterScience (Online service), Proteomics in Practice : A Guide to Successful Experimental Design. Hoboken, NJ: Wiley-VCH (2008).

41. Valdés A, Holst BS, Lindersson S, Ramström M. Development of MS-based methods for identification and quantification of proteins altered during early pregnancy in dogs. J Proteomics. (2019) 192:22332. doi: $10.1016 /$ j.jprot.2018.09.004

Conflict of Interest: The authors declare that the research was conducted in the absence of any commercial or financial relationships that could be construed as a potential conflict of interest.

Copyright (C) 2020 Franco-Martínez, Horvatić, Gelemanović, Samardžija, Mrljak, Contreras-Aguilar, Martínez-Subiela, Dąbrowski and Tvarijonaviciute. This is an open-access article distributed under the terms of the Creative Commons Attribution License (CC BY). The use, distribution or reproduction in other forums is permitted, provided the original author(s) and the copyright owner(s) are credited and that the original publication in this journal is cited, in accordance with accepted academic practice. No use, distribution or reproduction is permitted which does not comply with these terms. 